can be checked by readings on a horizontal graduated scale at a distance of 30 or $40 \mathrm{ft}$. If the drum scale is uniform, regular steps on the drum will correspond to regular steps on the scale.

\title{
Reporting Near Misses at Sea
}

\section{Nicolson}

I. INTRODUCTION. Not surprisingly much of the work that has been done on collision at sea has involved the study of collisions which have actually occurred. There must however be a wealth of untapped data relating to 'near misses' judging by the hair-raising stories often told by ships' officers. These accounts, sometimes of ships passing one another so closely in fog that human sounds have been heard, are doubtless subject to embellishment but are, nevertheless, the stuff that nightmares are made of.

An interesting point which (perhaps predictably) features in many such stories is that the navigator presents himself as a victim of circumstances rather than one who has suffered the effects of a wrong decision. Curiously the 'other ship' sometimes shares this diplomatic immunity. Discounting 'acts of God' then, is there room for a category of encounter in which blame is minimized or even ruled out? In the discussion following a recent paper ${ }^{1}$ Captain F. J. Wylie states that between 1948 and 1966 most of the collisions he had studied which had come to court had, according to the Judge, been due to personal error (generally related to the Rules or misinterpretation of radar information). This no doubt reflects the situation in a true light provided one accepts that it may occasionally be necessary to distinguish between 'personal error' and blame. The two might not go together, for example, when the error is due to overloading of the human system or under-exposure to congested waters-a view which appears to be gaining support in some quarters.

2. THE NEED FOR A REPORTING PROCEDURE. On the air side there is a well established system of reporting near misses and their circumstances ${ }^{2}$ but whilst many ships have for some time (and very effectively) carried a file of actual collision case studies ${ }^{3}$ no such system has yet been extended to selected near misses although useful work is being done in the Dover Strait. ${ }^{4}$

In the air, when one aircraft 'infringes the integrity' of another's airspace passing, say, within three miles, then a report is required. This procedure however is not of a punitive nature and the report goes, confidentially, before a joint airmiss working group who then categorize the incident according to its seriousness-'near hit', 'nominal infringement' \&c. Such a system, which runs parallel to but independently of the enquiry system, must reflect a need in shipping. The main difficulty with such an analogy, of course, lies in the vast difference in control factor between aircraft and shipping, and this being the case it is probably true to say that an appreciation of the build-up of events by the navigator would have more relevance to shipping than to aircraft. A marine reporting scheme would therefore be better directed at the training function than at research and the improvement of control systems, nevertheless adding to the statistical significance of existing research conclusions. 
Surely the seafaring community has a responsibility to itself to provide the machinery for such a system and to find and maintain a balance between the 'punitive' and 'curative' approaches without disturbing the integrity of the Collision Regulations; to create a climate in which navigators would be prepared to exchange views and experiences in a constructive atmosphere. Since it is likely that relatively young officers would feature in such cases, the navigation schools might serve as a useful starting point, adding to their already excellent work by, for example, introducing periodic discussion seminars to their time-tables for First Mate and Masters' Certificates, the results of which could be documented, analysed and eventually circulated to ships and research centres. One possible way of getting the required information from the ship to the seminar room would be to extend on a purely voluntary basis, the idea of the cadet log book (which already forms an important part of most cadets' training) to Master's Certificate level, in the form of a strictly unofficial 'officers log book'. In this way officers' experiences could be fed back to them after discussion and analysis.

The incident described in the next section happened long enough ago not to matter too much and is probably far from being a watertight case anyway; it is, however, a simple example, if a rather unusual one, of the sort of thing which could bear discussion and illustrates the possible influence of a particular set of circumstances that could have ended in disaster.

3. A specimen 'Near miss'. This took place in the Coral Sea in 1965. Times have been reconstructed from memory.

The conditions: visibility was approximately 10 miles with isolated rain showers, a $2-3$ foot confused sea, light confused wind gusting at times and a completely overcast sky.

The ship: a modern cargo liner, speed 18 knots, equipped with magnetic and gyro compasses, was proceeding by automatic pilot; the latter had a history of unreliability but was now considered to be operating normally. The only man on the bridge was a relatively inexperienced third officer who was, at the time, keeping the radar on standby due to the occasional rain showers and checking the ship's head against the standard magnetic compass every 10 minutes or so. Open waters; no shipping about.

The order of events :

1000 Heading checked and found correct $\left(055^{\circ}\right)$.

1007 A ship sighted about 2 points $\left(22 \frac{1}{2}^{\circ}\right)$ to starboard, crossing and showing a narrow aspect; bearing decreasing, range estimated at 8 miles.

I 008 Chief officer 'phoned the bridge requiring figures from the log book.

10 1 0 Target no longer visible, obscured presumably by a rain shower. Visibility at own ship still good. At this point the radar was switched on; no target was detected but a patch of rain clutter was observed about where the target would have been expected on the PPI.

I012 Own ship entered a rain shower; extensive rain clutter starting to appear on the radar rendering it virtually useless.

1012 Heading checked. Gyro and autopilot found to be $45^{\circ}$ in error to port. Ship's head was now $010^{\circ}$. The helmsman was summoned from the deck by mouth-whistle; steering changed to manual and kept on the present heading by the third officer.

IOI 3 Helmsman on the wheel steering by magnetic compass. 
I0I4 Third officer attempted to locate the target visually and on radar without success; rain clutter gradually clearing.

I0I 5 At this point the officer was unable to decide how much, if any, of the undetected $45^{\circ}$ swing had occurred before (or after) the first sighting of the other ship at 1007 , or indeed whether the swing had been an even one. In short he had an approaching target forward of the beam but did not know where it was relative to his bow.

1015 Sounded one prolonged blast on the ship's whistle; double ring stop on telegraph; 'phoned master.

I01 7 Master and chief engineer to the bridge; master assumed control.

1021 Rain cleared; target sighted well clear to port; full ahead; master and chief engineer below.

Figure I shows the situation at 1007 , the time of first sighting. The possible situations at I 0 I5, however, are endless depending upon the time, duration and nature of the swing. Figure 2 shows the rather 'primitive' picture as visualized at the time by the officer in question, assuming the target took no action and had a speed similar to own ship's. In Fig. 2 :

(a) Relative position of the target at 1015 assuming the entire swing occurred instantaneously at (or just after) r 007 (i.e. officer on 'phone)

(b) Relative position of the target at IO I 5 assuming the entire swing occurred instantaneously at or just before 1012.

(c) Relative position of the target at 1015 assuming half the swing occurred before 1007 ; other half instantaneously just after 1007 (officer on 'phone).

(d) Relative position of the target at 1015 assuming half the swing occurred before 1007 ; other half instantaneously at 1012.

(e) Relative position of the target at 1015 assuming the entire swing occurred before 1007 .

(f) Relative position of the target on actual sighting at 102 I showing that the swing had in fact occurred before 1007 .

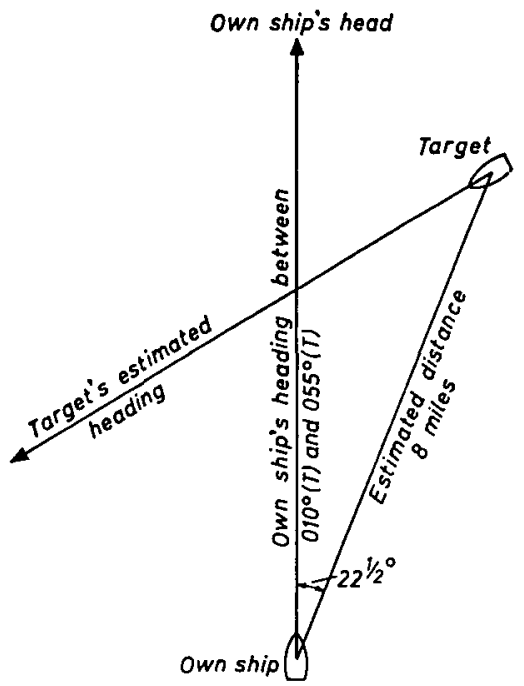

FIG. I. First sighting at 1007 


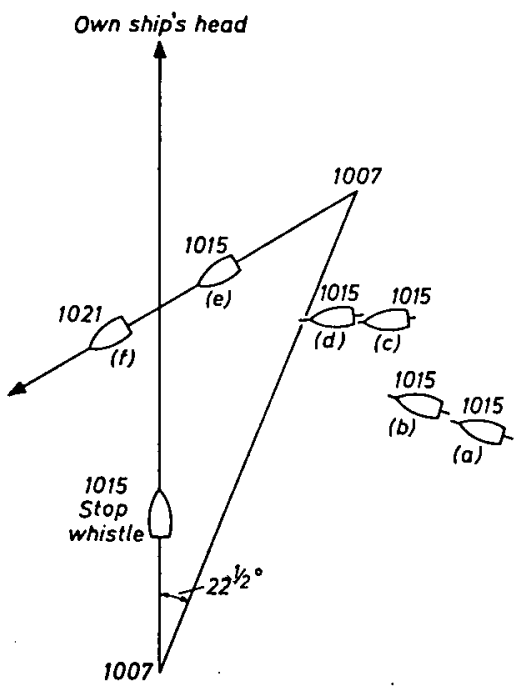

FIG. 2. Some possible situations at io I 5

4. Conclusion. In this case a chance combination of conditions and events masked the swinging of the ship leading to a potentially dangerous close-quarters situation; in normal circumstances an apparent shift of wind, sea, cloud formation, Sun, \&c. would have given the navigator a clue. Had collision resulted, the press would no more have appreciated these points than they did the circumstances of the recent Achilles collision in the Dover Strait, and the matter would, in all likelihood, have been reported as a collision involving two ships in open waters with virtually clear weather; and the seafaring community would have shaken their heads in exasperation-those of them, that is, who did not themselves have a story to tell.

The officer involved felt that he had, to some extent, been a victim of circumstances and would have liked to have discussed his experience with someone outside the ship. (The master and chief engineer had not been happy about the incident and were ill-disposed to discussing it.) Things being what they are it was soon forgotten. He summarized his own possible mistakes as follows :

(i) The ship's head should have been checked more frequently (say, every 5 minutes)

(ii) An occasional glance astern (in such uncertain conditions) might have revealed a 'bend' in the wake.

(iii) He should have insisted, in the circumstances, on having a helmsman on the wheel (in spite of the captain and chief officer wanting an extra man on deck).

(iv) He should have noticed an anomaly when first observing the bearing (on the starboard wing gyro repeater) of the approaching vessel.

(v) A wide course alteration might have been preferable but with rain about there was the possibility of further involvement with a third ship.

As far back as 1955 Commander Sharpey-Schafer wrotes 'There must also be a fairly large number of near misses and, daily, officers have to consider the impli- 
cations of situations which could give rise to collision. ...' How much more productive the above 'self-analysis' might have been if carried out round a table in the company of fellow navigators and experienced teachers, leading to a better and more universal understanding of these 'implications'; leading perhaps to the beginnings of an explanation of why, as Figs. 6 and 8 in Captain Cockcroft's Statistics of Collision 6 admirably illustrate, not a few collisions look, with hindsight, almost as though they were contrived.

\section{RE FEREN CES} $23^{8}$.

1 Jones, K. D. and Perkins, C. S. (1975). Automatic plotting radars. This Journal, 29,

2 Accidents to aircraft in the British register (published annually together with statistics of airmiss incidents), C.A.A., London.

3 Ship casualty report scheme: General Council of British Shipping, London.

4 Enden, R. K. (1976). The Dover Strait Information Service: recent progress. This Journal, 29, 263.

5 Sharpey-Schafer, J. M. (1955). Collision at Sea. This Journal, 8, 261

- Cockcroft, A. N. (1976). Statistics of collisions at sea. This Journal, 29, 215.

\section{Saving Money by Cutting Corners}

\section{J. D. Proctor}

THIs note assesses the savings in (time- and fuel-dependent) direct operating costs that are possible if every turning point on an airway is passed on the inside. Figure I shows a route with turning points at $\mathrm{A}, \mathrm{B}$ and $\mathrm{C}$. If a pilot follows the standard procedure of flying along $A B$ until he is sure that he has passed $B$, his total track distance is $(c+d+a+b)$.

To simplify the mathematics let us assume that he turns instead through half the required angle at a distance $d$ before he reaches $B$ and completes the turn after passing $\mathrm{B}$ abeam (and very close). His track distance will be $(c+e+f)$. The difference in distance $\delta$, representing the saving, is therefore $(d+a+b)-(e+f)$.

In Fig. 1 :

$$
\begin{aligned}
x & =a \cos \theta \\
e & =2 d \cos \theta / 2 \\
b & =y \\
(x+y) & =(f+d) \bumpeq(a \cos \theta+b) \\
\therefore \delta & =d+a+b-2 d \cos \theta / 2-a \cos \theta-b+d \\
& =a(1-\cos \theta)+2 d(1-\cos \theta / 2)
\end{aligned}
$$

